\title{
Caput epididymitis but not orchitis was induced by vasectomy in a murine model of experimental autoimmune orchitis
}

\author{
Ning Qu, Hayato Terayama, Munekazu Naito, Yuki Ogawa, Shuichi Hirai, Miyuki Kitaoka, \\ Shuang-Qin Yi and Masahiro Itoh \\ Department of Anatomy, Tokyo Medical University, Tokyo 160-8402, Japan \\ Correspondence should be addressed to N Qu; Email: quning@tokyo-med.ac.jp
}

\begin{abstract}
Immunization of mice with viable syngeneic testicular germ cells (TGC) alone can induce autoimmune responses against autoantigens of both round and elongating spermatids, resulting in the development of experimental autoimmune orchitis (EAO). Histological lesions in this EAO model without an adjuvant are characterized by lymphocytic infiltration into the testes, spermatogenic disturbance, and a complete lack of epididymitis. In this study, we investigated the effects of vasectomy (Vx) on TGC-induced EAO expecting that Vx augments the severity of testicular inflammation in $\mathrm{A} / \mathrm{J}$ mice. The results showed that mice receiving Vx alone exhibited no significant inflammatory cell response in either the testes or epididymides, and mice receiving shamVx + TGC immunization had EAO with no epididymitis. In sharp contrast, no EAO was found in the testes of any mice receiving Vx+TGC immunization. Instead, caput epididymitis involving CD4 + T cells, CD8 + T cells, B cells, and macrophages were induced in them with striking elevation of the tissue levels of both IL6 and IL10 mRNA. Furthermore, serum autoantibodies induced by shamVx + TGC immunization were reactive with both round (immature) and elongating (mature) spermatids; however, those induced by Vx+TGC immunization were specific to acrosomes of mature spermatids and spermatozoa. These unexpected results indicate that $\mathrm{Vx}$ may induce the mode by which autoreactive lymphocytes gain access to TGC autoantigens in the epididymides, leading to autoimmune responses against the autoantigens of mature rather than immature spermatids.
\end{abstract}

Reproduction (2008) 135 859-866

\section{Introduction}

Vasectomy $(\mathrm{Vx})$ is a simple, effective, and widely used method of male contraception. The nature and incidence of local and systemic changes induced by $\mathrm{V} x$ continue to be of interest. Many studies have revealed the induction of spermatogenic disturbance following $V x$ whereas numerous others have not. Some studies revealed the induction of humoral and cell-mediated autoimmune responses directed against sperm antigens after $V_{x}$ (Ansbacher 1973, Alexander \& Tung 1977, Herr et al. 1987, Nashan et al. 1990, Flickinger et al. 1994, 1995).

Experimental autoimmune orchitis (EAO) is one of the models of immunologic male infertility characterized by lymphocytic infiltration into the testes, leading to spermatogenic disturbance. In most EAO models, epididymitis occurs prior to orchitis, and the inflammatory lesions of the epididymides usually become more severe than those in the testes (Sato et al. 1981, Taguchi \& Nishizuka 1981, Tung et al. 1987, Roper et al. 1998). Taguchi \& Nishizuka (1981) were the first to investigate the effects of $V x$ on $\mathrm{EAO}$ in mice. They found that EAO with epididymitis could spontaneously develop after neonatal thymectomy on day 3 (day $3 \mathrm{Tx}$ ) without the use of any adjuvant in
$(\mathrm{C} 57 \mathrm{Bl} / 6 \times \mathrm{A} / \mathrm{J}) \mathrm{F} 1$ mice. In this disease model, the incidence of EAO was found to increase when day $3 \mathrm{Tx}$ mice received $V x$ on day 60 . Later, Kojima \& Spencer (1983) also reported that $V x$ increased the incidence of testicular atrophy in day $3 \mathrm{Tx}$ mice when compared with those without $\mathrm{Vx}$ in Balb/c strain.

We previously demonstrated that immunization of $\mathrm{C} 3 \mathrm{H} / \mathrm{He}$ and $\mathrm{A} / \mathrm{J}$ mice with viable syngeneic testicular germ cells (TGC) alone induces EAO without an adjuvant (Itoh et al. 1991a, 1991b, 1995, Tokunaga et al. 2008). However, this EAO model is very unique in which orchitis can occur without epididymitis. This biological phenomenon promoted us to investigate the effect of $V x$ on EAO. In this study, we examined $V x$ in TGC-immunized mice expecting that $V x$ augments the severity of both testicular and epididymal inflammations of autoimmune origin.

\section{Results}

The incidence and severity of the testicular and epididymal lesions are summarized in Table 1 . The sham $V x+$ PBS group showed normal spermatogenesis 
Table 1 The effects of vasectomy on testicular germ cells (TGC)-induced experimental autoimmune orchitis (EAO).

\begin{tabular}{|c|c|c|c|c|c|c|c|c|}
\hline \multirow[b]{2}{*}{ Treatments } & \multirow[b]{2}{*}{$n$} & \multirow[b]{2}{*}{$\begin{array}{l}\text { Orchitis } \\
\text { Incidence } \\
(\%)\end{array}$} & \multirow[b]{2}{*}{$\begin{array}{l}\text { Epididymitis } \\
\text { Incidence } \\
(\%)\end{array}$} & \multicolumn{2}{|c|}{ Autoanltibodies } & \multicolumn{3}{|c|}{ Spermatogenic disturbance } \\
\hline & & & & $\begin{array}{c}\text { Incidence } \\
(\%)\end{array}$ & Ig class & $\begin{array}{c}\text { Incidence } \\
(\%)\end{array}$ & $\begin{array}{c}{ }^{\mathrm{a}} \text { Grade } \\
(\text { mean } \pm \text { s.E.M. })\end{array}$ & $\begin{array}{l}{ }^{\mathrm{b}} \text { Apoptosis } \\
(\text { mean } \pm \text { S.E.M. })\end{array}$ \\
\hline None & 8 & 0 & 0 & 0 & None & 0 & 0 & $0.48 \pm 0.11^{\mathrm{h}}$ \\
\hline ShamVx+PBS & 8 & 0 & 0 & 0 & None & 0 & 0 & $0.52 \pm 0.18^{\mathrm{i}}$ \\
\hline $\mathrm{Vx}+\mathrm{PBS}$ & 10 & 0 & $10^{\mathrm{C}}$ & 100 & $\begin{array}{l}\lg G \\
\lg M\end{array}$ & 100 & $3.13 \pm 0.07^{\mathrm{e}}$ & $0.78 \pm 0.03^{j}$ \\
\hline ShamVx+TGC & 8 & 100 & 0 & 100 & $\begin{array}{l}\lg G \\
\lg A \\
\lg M\end{array}$ & 100 & $2.17 \pm 0.08^{f}$ & $0.03 \pm 0.01^{\mathrm{k}}$ \\
\hline $\mathrm{Vx}+\mathrm{TGC}$ & 22 & 0 & $100^{\mathrm{d}}$ & 100 & $\begin{array}{l}\lg G \\
\lg M\end{array}$ & 100 & $1.70 \pm 0.29^{g}$ & $0.28 \pm 0.05^{1}$ \\
\hline
\end{tabular}

$P<0.05=$ e versus $g$, i versus $k$, i versus $\mathrm{l}, \mathrm{j}$ versus $\mathrm{l}, \mathrm{k}$ versus $\mathrm{l}$, $\mathrm{h}$ versus $\mathrm{k}$ and $\mathrm{h}$ versus $\mathrm{l}$; not significant $=\mathrm{f}$ versus $\mathrm{g}$, $\mathrm{h}$ versus $\mathrm{j}$, i versus $\mathrm{j}$ and $\mathrm{i}$ versus $\mathrm{h}$. ${ }^{a}$ The level of spermatogenic disturbance was graded, on a 0-4 scale, using the degree of percentage of the seminiferous tubules showing the disappearance of mature germ cells and desquamation of germinal epithelium in the prepared sections: grade $0,0 \%$; grade 1, 1-5\%; grade 2, 6-25\%; grade 3, 26-50\%; and grade 4, 51-100\%. b Number of TUNEL-positive cells/round or oval-shape of seminiferous tubules. 'Inflammatory cells focally filtrated into the corpus but not the caput epididymis. ${ }^{d}$ Inflammatory cells infiltrated into the caput epididymis.

with no inflammatory signs in either the testes or epididymides (Fig. $1 \mathrm{a}$ and $\mathrm{e}$ ). In the $\mathrm{Vx}+$ PBS group, the testes were characterized by significant aspermatogenesis without inflammatory cell infiltration. In their epididymides, there were many retained spermatozoa in the epididymal ducts with no significant inflammatory cell infiltration (Fig. $1 b$ and $f$ ). Only one out of the ten mice in the Vx+PBS group exhibited the focal lymphocytic infiltration into the interstitium of the corpus of epididymis (Table 1). In the sham $\mathrm{x} x+\mathrm{TGC}$ group, orchitis characterized by lymphocytic infiltration and the resultant aspermatogenesis was seen in all examined mice with no epididymitis (Fig. 1c and g). Apoptotic germ cells of this group were much lower in number because of removal of stem cells from the damaged seminiferous tubules (Table 1). In sharp contrast, unexpectedly, no lymphocytic infiltration was found in the testes of any of the $V x+$ TGC group (Fig. 1d). Furthermore, the spermatogenic disturbance was less severe than that in the $\mathrm{Vx}+$ PBS group, and the number of apoptotic germ cells in the $V x+T G C$ group was significantly higher than that in the sham $V x+T G C$ group and lower than that in the $V x+P B S$

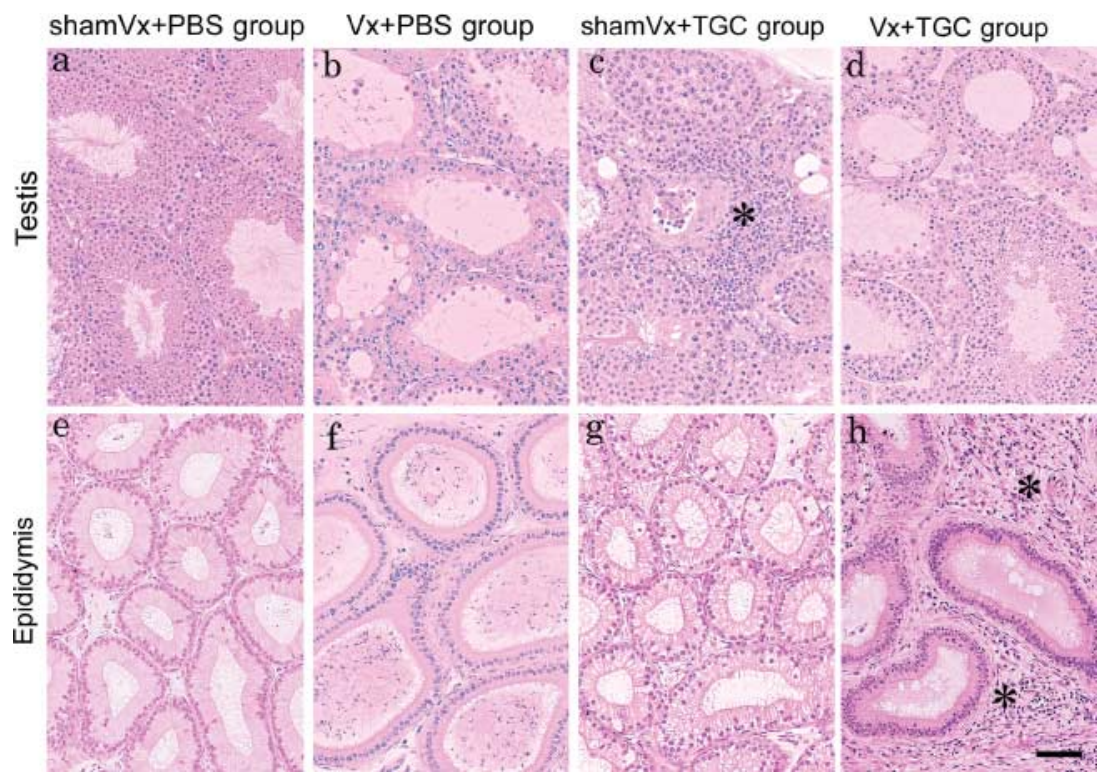

Figure 1 Testicular and epididymal sections from ( $a$ and e) the sham $V x+P B S$ ( $b$ and $f$ ) $V x+P B S$, (c and g) sham $V x+T G C$ and $(d$ and $h$ ) $V x+T G C$ groups. Testis sections of (a) sham $V x+P B S$ group showing intact seminiferous tubules exhibiting all stages of maturation of the germinal epithelium from spermatogonia to spermatozoa; (b) $\mathrm{Vx}+\mathrm{PBS}$ group showing suppression of spermatogenesis without inflammatory cell infiltration; (c) sham $\mathrm{V} x+\mathrm{TGC}$ group showing damaged seminiferous tubules surrounded by many inflammatory cells and (d) $V x+T G C$ group showing slight suppression of spermatogenesis without inflammatory cell infiltration, Sections of the caput of the epididymis from (e) shamVx+PBS group showing closely packed epididymal ducts with little interstitium; (f) $\mathrm{Vx}+\mathrm{PBS}$ group showing enlarged ducts containing many spermatozoa; $(\mathrm{g})$ sham $\mathrm{V} x+\mathrm{TGC}$ group showing the lack of evidence of inflammatory cell response; and ( $h$ ) Vx+TGC group showing the widened interstitium containing many lymphocytes. Asterisks indicate areas of lymphocytic inflammation. Bar, $20 \mu \mathrm{m}$. 
group (Table 1). Alternatively, in the Vx+TGC group, extensive interstitial inflammation was found in the caput epididymides away from the vasectomy site (Fig. $1 \mathrm{~h}$; Table 1 ). In the sham $V x+T G C$ group, many CD4 + T cells with significant number of CD8+T and B220 cells infiltrated into the testes while no positive cells were found in testes of the $\mathrm{Vx}+\mathrm{TGC}$ group (Fig. 2; Table 1). Instead, CD4 + T, CD8 + T, and B220 cells were found in the caput epididymides of the $\mathrm{Vx}+\mathrm{TGC}$ group, although no or few lymphocytes could be observed in the caput epididymides of the other animal groups (Fig. 3; Table 1). A significant number of F4/80-positive macrophages, differing from lymphocytes, were detected in the epididymides of all animal groups (Fig. 4). However, the macrophages in the $\mathrm{V} x+\mathrm{TGC}$ group tended to infiltrate into the epithelial layers of the epididymal ducts when compared with the other four groups.

On reaction of sera with normal frozen sections of seminiferous tubules and epididymal ducts, anti-TGC autoantibodies were detected in the $V x+P B S$, sham $V x+T G C$, and $V x+T G C$ groups but not in the untreated and shamVx+PBS groups (Fig. 5). The immune sera contained both $\lg G$ and $\lg M$ autoantibodies. In addition, IgA autoantibodies were further detected in the shamVx+TGC group (Table 1). Faint immunostains were detected in various types of germ cells in the seminiferous tubules in the $\mathrm{V} x+\mathrm{PBS}$ group.

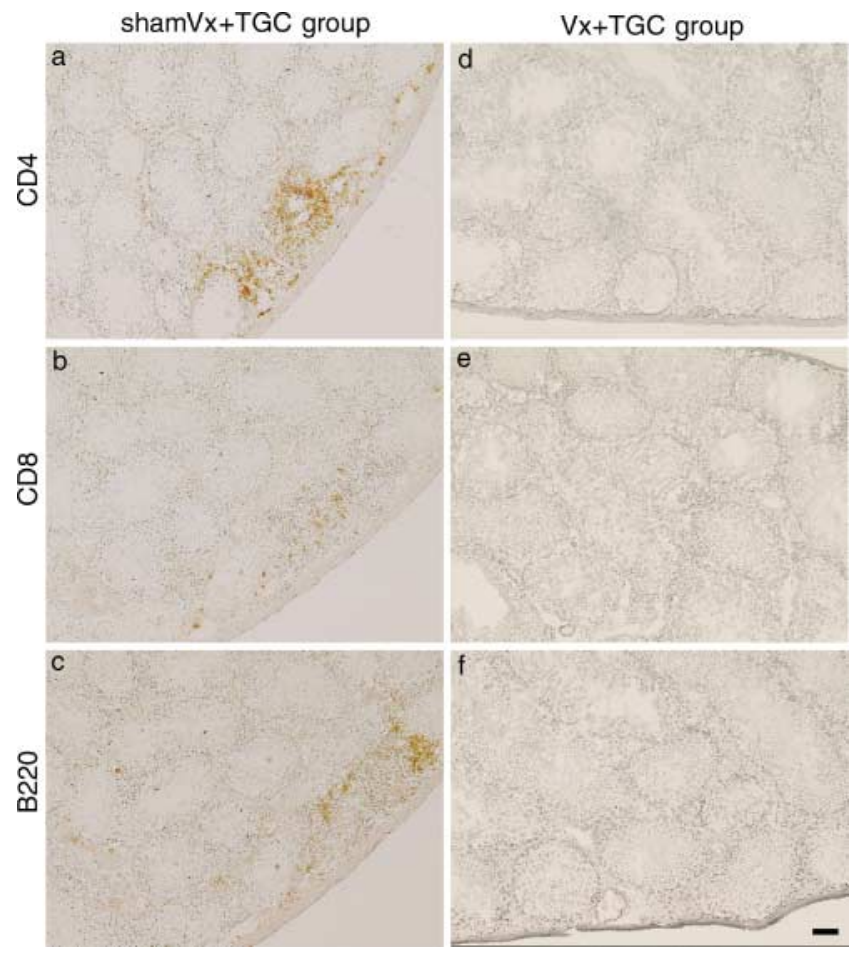

Figure 2 Testicular sections from $(a-c)$ sham $V x+T G C$ and $(d-f)$ $\mathrm{Vx}+\mathrm{TGC}$ groups examined with the use of mAbs to (a and d) CD4, (b and e) CD8, and (c and f) B220. Note the infiltration of CD4-, CD8-, and B220-positive lymphocytes in the shamVx+TGC but not in $\mathrm{Vx}+\mathrm{TGC}$ group. Bar, $50 \mu \mathrm{m}$.
In the sham Vx+TGC group, the serum autoantibodies preferentially reacted with immature spermatids in the seminiferous tubules and epididymal spermatozoa in the caput but not cauda of epididymis. By contrast, in the $\mathrm{Vx}+\mathrm{TGC}$ group, the autoantibodies specifically reacted with the crescent-shaped acrosomes of mature spermatids and spermatozoa.

To determine why $V x$ treatment induced caput epididymitis but not orchitis after TGC immunization, the expression of inflammation-related genes was examined in both testicular and epididymal tissues in each animal group (Fig. 6). In the epididymides, $V x+$ PBS group showed strong expression of the IFN- $\gamma$ (Ifng), IL-6 (II6), and IL-10 (I/10) genes while no striking change was detected in the epididymal cytokines in the sham $V x+T G C$ group. In the $V x+T G C$ group, the gene expression of epididymal cytokines was increased similarly to that in the $\mathrm{Vx}+\mathrm{PBS}$ group. In particular, the IL-6 level was more significantly increased while both the IFN- $\gamma$ and IL-10 levels tended to decrease when compared with the $\mathrm{Vx}+\mathrm{PBS}$ group. In contrast, some testicular cytokines were significantly but slightly increased only in the sham $\mathrm{V} x+\mathrm{TGC}$ group.

\section{Discussion}

In this study, we demonstrated that $\mathrm{Vx}$ did not augment the severity of TGC-induced EAO although it had been

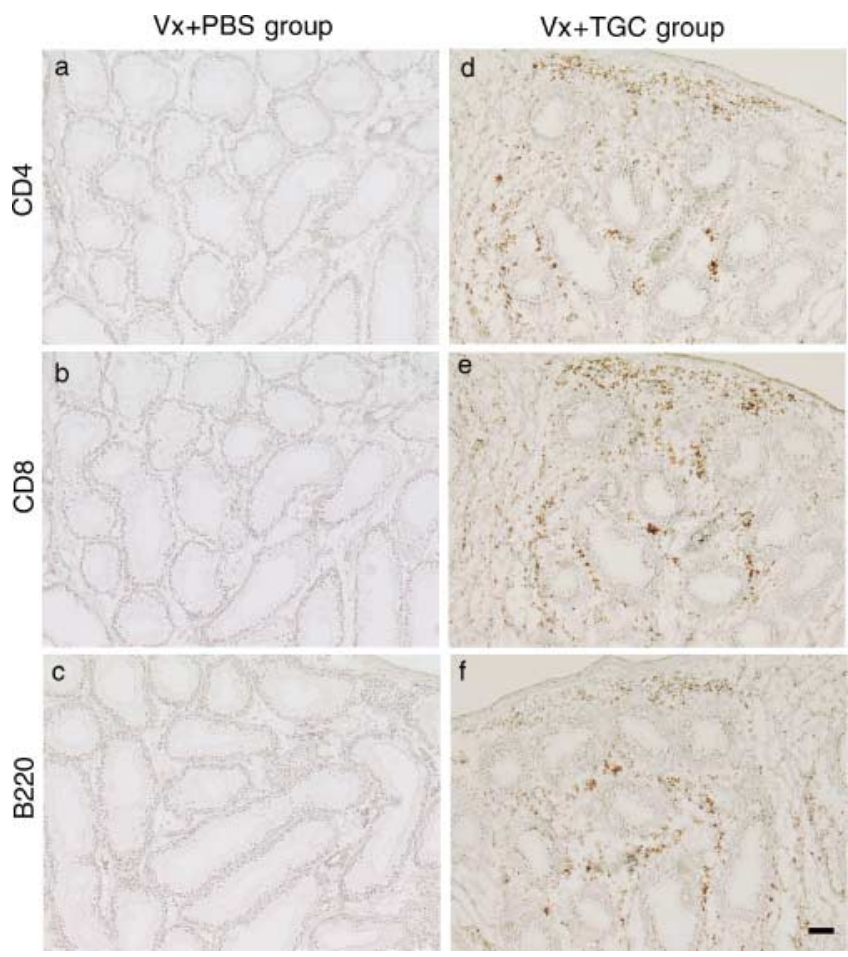

Figure 3 Epididymal sections from $(a-c) V x+P B S$ and $(d-f) V x+T G C$ groups examined with the use of $\mathrm{mAbs}$ to $(a$ and d) CD4, (b and e) CD8, and ( $\mathrm{C}$ and $\mathrm{f}$ ) B220. Note the infiltration of CD4-, CD8-, and B220positive cells in the $\mathrm{Vx}+\mathrm{TGC}$ but not in $\mathrm{Vx}+\mathrm{PBS}$ group. Bar, $50 \mu \mathrm{m}$. 


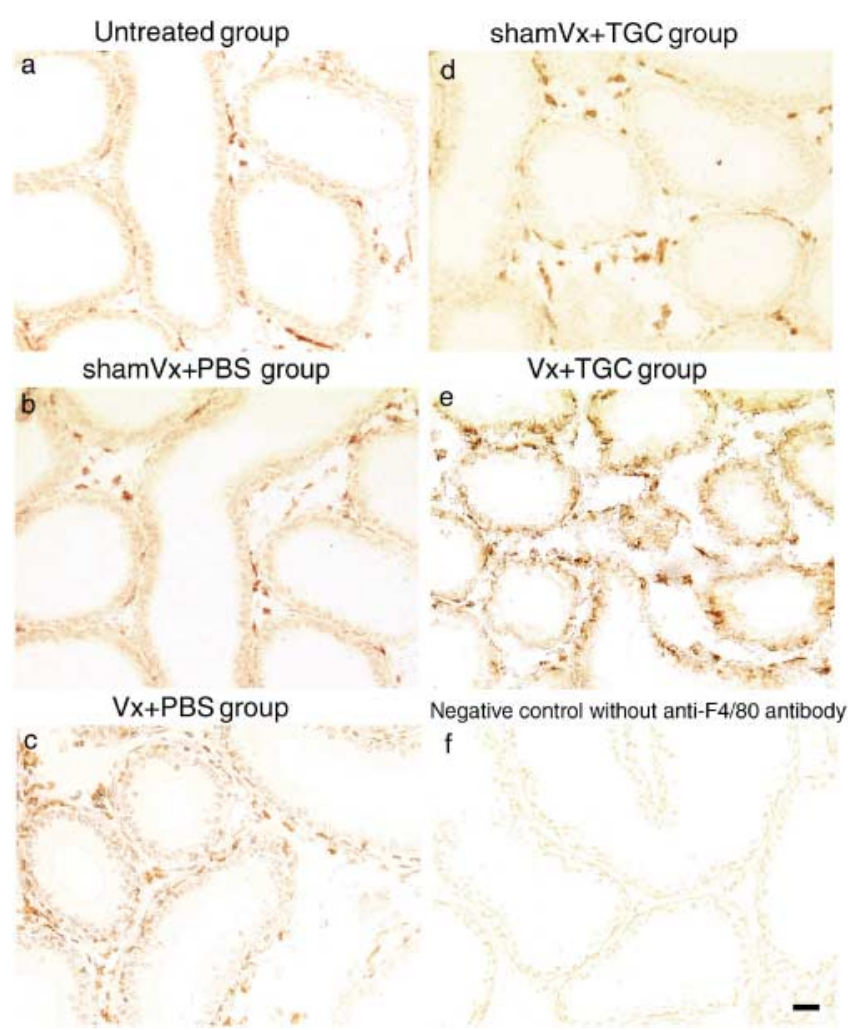

Figure $4 \mathrm{~F} 4 / 80$ antigen-positive cells in epididymal sections obtained from mice in the (a) untreated (b) shamV $x+P B S$, (c) $V x+P B S$, (d) shamVx+TGC, and (e) Vx+TGC groups. It should be noted that many macrophages had infiltrated into the epithelial layers of the epididymal ducts in $\mathrm{Vx}+\mathrm{TGC}$ group. (f) Negative control without anti-F4/80 antibody. Bar, $20 \mu \mathrm{m}$.

reported that $V x$ makes day 3 Tx-induced EAO more severe (Taguchi \& Nishizuka 1981, Kojima \& Spencer 1983). Conversely, Vx suppressed EAO and alternatively induced caput epididymitis in the TGC-induced model.

The lymphocytic population in the epididymitis in the $\mathrm{Vx}+\mathrm{TGC}$ group was composed of CD4 $+\mathrm{T}, \mathrm{CD} 8+\mathrm{T}$, and $\mathrm{B}$ cells and macrophages, like in EAO lesions in the sham $V x+T G C$ group (Itoh et al. 1991b). Interestingly, the autoantibodies in the $\mathrm{Vx}+\mathrm{TGC}$ group were found to be against the heads of mature spermatids and spermatozoa although those in the $\mathrm{Vx}+\mathrm{PBS}$ or sham $V x+T G C$ group were against more immature germ cells. Taguchi \& Nishizuka (1981) have reported that autoimmune epididymitis had been induced prior to orchitis in day 3 Tx mice. Furthermore, their immunohistochemical examination of day 3 Tx mice demonstrated that the serum autoantibodies were against the crescent-shaped heads of elongated spermatids and spermatozoa. Therefore, the presence of autoantibodies against mature spermatozoa in both the day $3 \mathrm{Tx}$ - and $\mathrm{Vx}+\mathrm{TGC}$-induced models may be related to the autoimmune inflammation affecting the epididymis rather than the testis. It has been reported that the ducts of the caput epididymis are the sites of absorption of various materials leaving the testis (Hamilton 1972). Therefore, $\mathrm{Vx}$ may allow the epididymal ducts to absorb testis-secreting materials, including autoantigens of mature spermatids, more strongly and to leak or excrete some of the absorbed autoantigens to the outside of the ducts. Actually, Howards \& Johnson (1979) reported the leakage of epididymal spermatozoa from the ducts of the caput epididymis after $V x$ in hamsters. In preliminary experiments, we tried to induce autoimmune epididymitis by means of immunization with epididymal spermatozoa (instead of TGC) with or without $V x$. However, autoimmune epididymitis was never induced in them. This implies that the autoantigens of the mature spermatids in TGC rather than epididymal spermatozoa are important for $\mathrm{V} x+\mathrm{TGC}$-induced caput epididymitis. Unfortunately, Taguchi \& Nishizuka (1981), and Kojima \& Spencer (1983) did not document the histopathological effects of $V x$ on epididymitis in day 3 Tx-induced EAO. Therefore, it remains unknown whether $V x$ affects the severity of the autoimmune epididymitis of this model. Furthermore, it is also unclear why $v x$ augmented day $3 \mathrm{Tx}$-induced EAO. We suppose that the epididymitis induced by day 3 Tx may become more severe with $\mathrm{Vx}$, leading to spreading of more inflammation to the testes. It has been demonstrated that autoreactive lymphocytes could preferentially gain access to the tubuli recti and the rete testis where the blood-testis barrier is incomplete (Dym \& Fawcett 1970, Aoki \& Fawcett 1975, Itoh et al. 1995, 1998). However, $V x$ may increase the hydrostatic pressure in the epididymal ducts rather than the tubuli recti and the rete tesits, resulting in possible leakage of more germ cell autoantigens into the epididymal interstitium. There may be other possibilities that blood flow or lymphatic drainage in the testis and epididymis is changed by $\mathrm{Vx}$. These factors may induce the different inflammatory responses between sham $\mathrm{V} x+\mathrm{TGC}$ - and $\mathrm{Vx}+\mathrm{TGC}-$ induced autoimmunity.

In this study, it was also unexpectedly found that the levels of IFN- $\gamma$, IL- 6 , and IL-10 in the epididymides strikingly increased with $\mathrm{Vx}$ alone. These elevated cytokine levels may also have affected the induction of epididymitis in the $V x+$ TGC group. Although it remains unknown which cell population produces each cytokine after $V x$, it was reported that epithelial and myoid cells of the epididymis produce IL-10 and IL-6 respectively, in cryptorchid cryptepididymis (Verajankorva et al. 2002). Clinically, the semen IL-6 level is increased in Vx reversal patients (Nandipati et al. 2005). We had showed that IL-6 administration reduced the incidence and severity of TGC-induced EAO ( $\mathrm{Li}$ et al. 2002). On the other hand, an in vitro study demonstrated that IL-6 had promoted apoptosis of germ cells in isolated seminiferous tubules in rats (Rival et al. 2006). IL-10 is ordinarily known to be an immunosuppressive cytokine. In EAO, adeno-associated virus-mediated human IL-10 gene transfer suppressed the development of the disease 

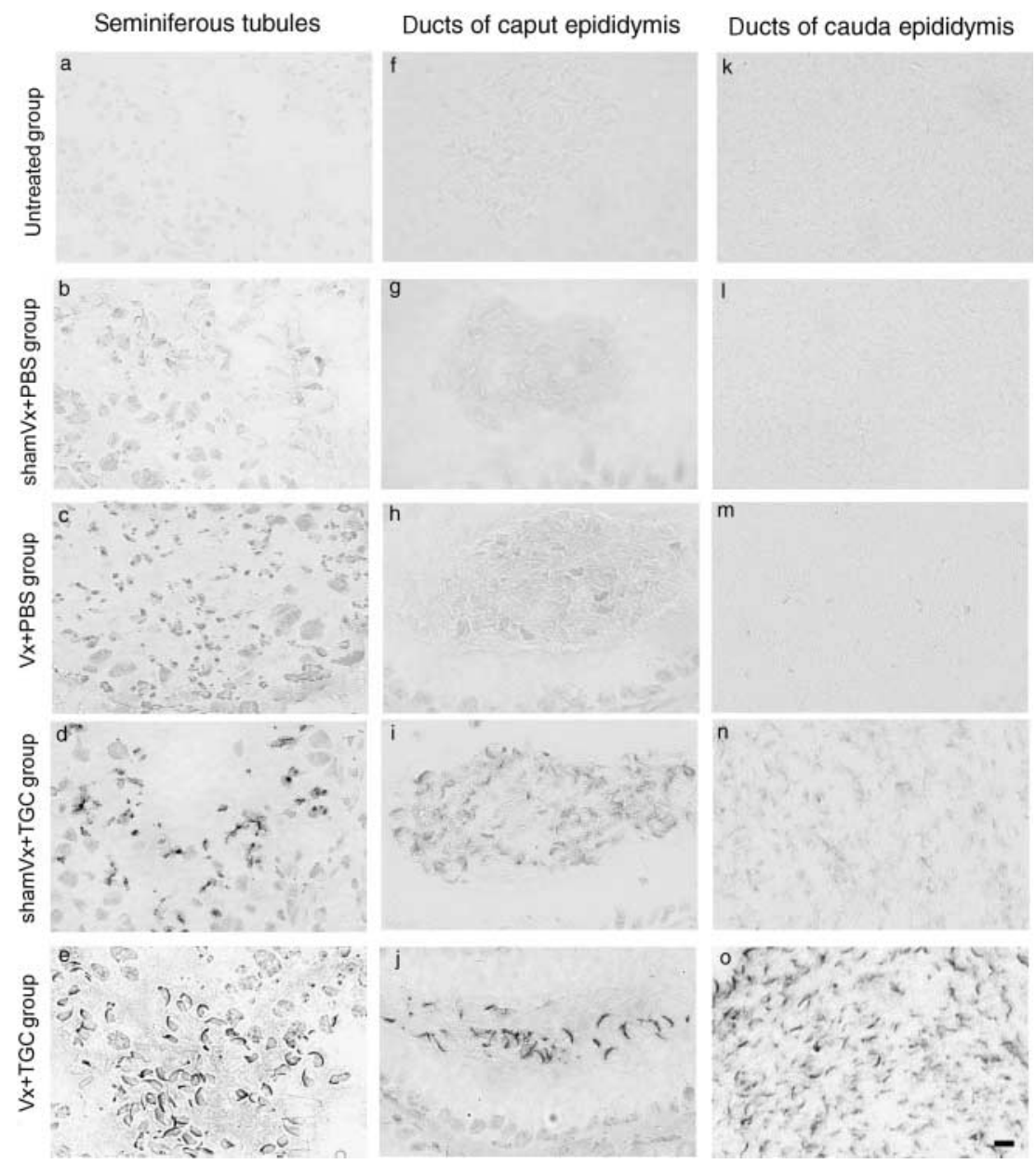
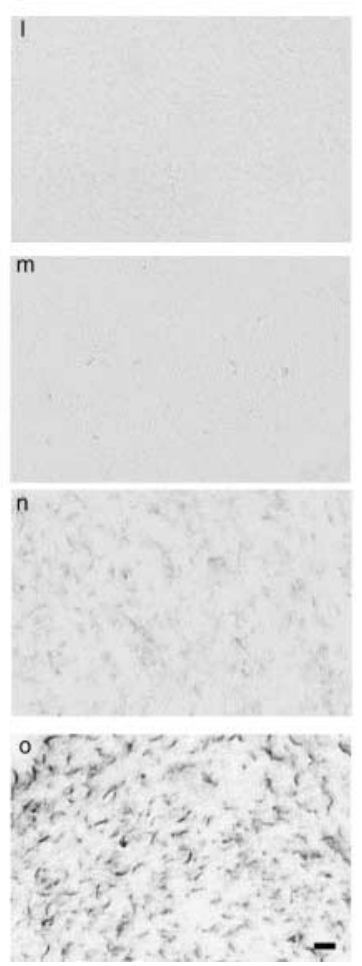

Figure 5 Normal frozen sections of seminiferous tubules and epididymal ducts reacted with diluted sera (50-fold) obtained from ( $\mathrm{a}, \mathrm{f}$ and $\mathrm{k}$ ) untreated, (b, g and I) shamVx+PBS, (c, h and $m) V x+P B S$, $(d, i$ and $n)$ sham $V x+T G C$, and $(e, j$ and $o)$ $V x+T G C$ groups followed by incubation with HRP-conjugated anti-mouse IgG. Note that the autoantibodies in the $\mathrm{Vx}+\mathrm{TGC}$ group specifically reacted with the crescent-shaped acrosomes of (e) enlongated (mature) spermatids in seminiferous tubules and ( $j$ and o) spermatozoa in ducts of both caput and cauda epididymis. Bar; $10 \mu \mathrm{m}$.
(Watanabe et al. 2005). However, it exerts the opposite effect in some autoimmune diseases including EAO (Rosenbaum \& Angell 1995, Hill \& Sarvertnick 2002, Kaneko et al. 2003, Tokunaga et al. 2008). Although pathophysiological effects of these two cytokines on the epididymal tissues remain unclear, the $\mathrm{Vx}$-induced elevation of the epididymal cytokines may attract inflammatory cells to the epididymis rather than the testis. In our next study, we will attempt to identify the cell population that secretes each cytokine in Vx+TGCinduced epididymitis by means of both immunohistochemistry and in situ hybridization.

In other experiments involving donor lymphocytes obtained from TGC-immunized mice, we examined an adoptive transfer of EAO (passive EAO) into recipient mice and found that the histopathology of passive EAO in the recipients differed from that in TGC-immunized donors (active EAO; Itoh et al. 1991b, 1992). Namely, the lesions in active EAO showed severe orchitis with a complete lack of epididymitis; however, the passive EAO was consistently accompanied by autoimmune epididymitis. Moreover, in some recipients, it was found that only autoimmune epididymitis had developed, i.e., without EAO. Although the reason for the different histopathologies of active and passive EAO remains unclear, this phenomenon may help us to elucidate the pathogenesis of $\mathrm{Vx}+\mathrm{TGC}$-induced epididymitis with suppression of EAO. There may be a possibility that lymphocyte traffic route is changed by $\mathrm{Vx}$, leading to epididymitis rather than orchitis. Comparative studies on shamVx+TGC and Vx+TGC groups with regard to the histopathology of adoptive transferred inflammation with donor lymphocytes are currently in progress.

\section{Materials and Methods}

\section{Animals}

Experiments were conducted with 8-week-old A/J male mice, weighing 25-28g. The animals were purchased from SLC (Shizuoka, Japan) and kept in the Laboratory Animal Center of Tokyo Medical University for 2 weeks before use. They were maintained at $22-24{ }^{\circ} \mathrm{C}$ and $50-60 \%$ relative humidity with a $12 \mathrm{~h}$ light:12 $\mathrm{h}$ darkness. The approval of the Tokyo Medical University Animal Committee was obtained for this study. 

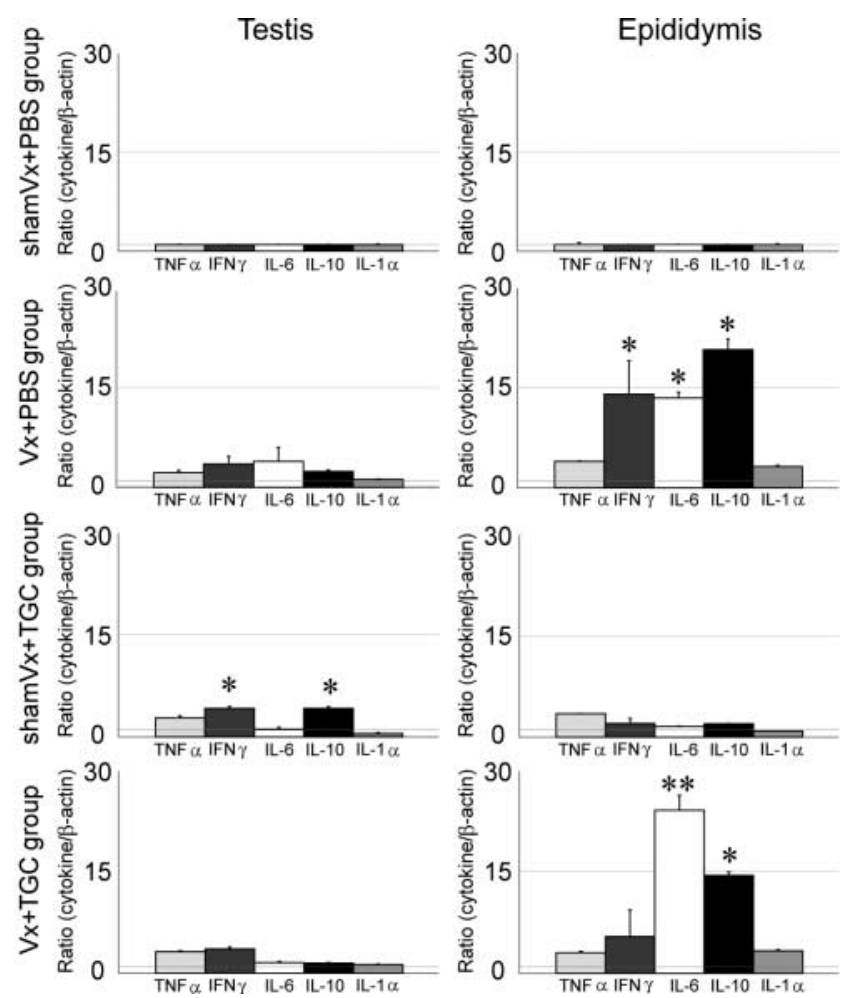

Figure 6 Expression of mRNAs of TNF- $\alpha$, IFN- $\gamma$, IL- $1 \alpha$, IL- 6 , and IL-10 in both testicular and epididymal tissues of the four experimental groups. Relative intensity was calculated after which the expression in the control (shamVx+PBS group) for each point had been normalized as 1 . Each bar represents the mean \pm s.D. $(n=3)$. Asterisks indicate $P<0.05$ versus control group. Double asterisks indicate $P<0.01$ versus control group.

\section{Vx treatment}

The operation was performed under sodium pentobarbital (50 mg/kg body weight, i.p) anesthesia via a lower midabdominal incision. The vas deferens on each side was exposed without causing injury to the adherent blood vessels and then occluding ligature comprising silk thread was applied to each vas deferens. Then the incision was closed in two layers. The procedure without the vasa deferentia being ligatured was performed as a shamVx for control mice. All operations were carried out under sterile conditions.

\section{TGC preparation}

Testes were excised from syngeneic mice, teased with scissors in cold Hanks' balanced salt solution (HBSS), and then passed through a stainless steel mesh. The TGC, including spermatogonia, spermatocytes, round spermatids, and elongating spermatids, were harvested by centrifugation at $400 \mathrm{~g}$ for $10 \mathrm{~min}$ and washed three times with cold HBSS, after determining their viability by means of trypan blue dye exclusion. The TGC suspension contained $>99 \%$ germ cells at all stages of spermatogenesis; the remainder $(<1 \%)$ comprised Sertoli cells and Leydig cells (Itoh et al. 1991a).

\section{Experimental design}

The mice were divided into five groups as follows: untreated normal group, naive mice without any treatments; sham $V x+P B S$ and sham $V x+T G C$ group mice received the sham operation on day 0 and then were injected subcutaneously with $200 \mu \mathrm{I}$ PBS and $1 \times 10^{7}$ TGC in $200 \mu \mathrm{l}$ PBS respectively, on days 7 and $21 ; \mathrm{Vx}+\mathrm{PBS}$ and $\mathrm{V} x+$ TGC group mice received bilateral $V x$ on day 0 and then were injected subcutaneously with $200 \mu \mathrm{I}$ PBS and $1 \times 10^{7}$ TGC in $200 \mu \mathrm{l}$ PBS respectively, on days 7 and 21 . Each group consisted of 8-22 mice (Table 1). Previous studies had already shown that EAO fully develops within 40 days after the first TGC immunization (Itoh et al. 1995). Therefore, on day 47, the mice were deeply anesthetized with pentobarbital (65 mg/kg body weight) and blood was collected from the hearts of all mice in the five groups. Serum samples from individual mice were stored at $-80{ }^{\circ} \mathrm{C}$ until used.

\section{Histopathological assessment}

The testes and epididymides were immediately removed from killed mice. For histological examination, the organs were fixed with Bouin's solution and embedded in plastic (Technovit 7100; Kulzer \& Co., Wehrheim, Germany) without cutting them to avoid artificial damage to the testicular and epididymal tissues. Sections $(5 \mu \mathrm{m})$ were obtained at 40-45 $\mu \mathrm{m}$ intervals and stained with Gill hematoxylin III and $2 \%$ eosin $\mathrm{Y}$ for light microscopical observation. The level of spermatogenic disturbance was graded on a 0-4 scale, using the degree of percentage of the seminiferous tubules showing the disappearance of mature germ cells and desquamation of germinal epithelium in the prepared sections: grade $0,0 \%$; grade $1,1-5 \%$; grade 2 , 6-25\%; grade 3, 26-50\%; and grade 4, 51-100\% (Itoh et al. 1991a). More than 200 round or oval-shaped seminiferous tubules were counted in each mouse.

For immunohistochemical and histochemical examinations, the testes and epididymides of experimental mice were put in OCT compound (Miles Laboratories, Naperville, IL, USA), and then frozen in liquid nitrogen and stored at $-80^{\circ} \mathrm{C}$ until used. Sections of $6 \mu \mathrm{m}$ were cut with a cryostat (CM1900; Leica, Wetzlar, Germany), dried in air, and then fixed in 95\% ethanol for $10 \mathrm{~min}$ at $-20^{\circ} \mathrm{C}$. The sections were rinsed in Tweenbuffered saline (TBS) and then incubated with Block Ace (Yukijirushi, Hokkaido, Japan) for $20 \mathrm{~min}$ at room temperature to inactivate endogenous peroxidase activity. After this treatment, serial sections were incubated for $2 \mathrm{~h}$ with rat anti-mouse CD4 monoclonal antibodies (1:100 dilution, class II MHC antigen-restricted T cells; BD Biosciences, San Jose, CA, USA), rat anti-mouse CD8 monoclonal antibodies (1:50 dilution, class I MHC antigen-restricted T cells; BD Biosciences), rat antimouse B220 monoclonal antibodies (1:100 dilution, B cells and some activated T cells; Santa Cruz Biotechnology Inc., Santa Cruz, CA, USA) or rat anti-mouse F4/80 monoclonal antibodies (1:100 dilution, macrophages; Abcam, Cambridge, UK). After washing, the sections were incubated for $30 \mathrm{~min}$ with rabbitanti-rat IgG (Vector Laboratories, Burlingame, CA, USA). Immunoreactive cells were visualized with a Vectastain $A B C$ 
Kit (Vector Laboratories) with $0.05 \%$ 3, 3- diaminobenzidine $4 \mathrm{HCl}$ (DAB, Nickel Solution) and $0.01 \% \mathrm{H}_{2} \mathrm{O}_{2}$ as the chromogen. The sections were finally counterstained with methyl green. Sections processed with PBS instead of the primary antibodies were used as negative controls.

For the detection of serum autoantibodies, frozen sections of testes and epididymides from normal mice were fixed with $95 \%$ ethanol for $10 \mathrm{~min}$ at $-20{ }^{\circ} \mathrm{C}$ and then incubated with 50 -fold serial dilutions of the collected sera for $60 \mathrm{~min}$ at room temperature. After rinsing in PBS, the sections were incubated for $60 \mathrm{~min}$ with horseradish peroxidase (HRP)-conjugated goat anti-mouse IgG and IgA (with 1:500 dilution each; ZyMax, South San Francisco, CA, USA), or rabbit anti-mouse IgM (1:200 dilution, ZyMax) at room temperature. After washing with PBS, the HRP-binding sites were detected with $0.05 \%$ $\mathrm{DAB}$ and $0.01 \% \mathrm{H}_{2} \mathrm{O}_{2}$ (Itoh et al. 1994).

For the detection of apoptotic cells, TUNEL was performed according to the method of Gavrieli et al. (1992) with a slight modification. Paraffin sections $(5-6 \mu \mathrm{m})$ from experimental mice were cut onto silane-coated glass slides, dewaxed with toluene, and rehydrated in an ethanol series. After washing with PBS, the sections were treated with $5 \mu \mathrm{g} / \mathrm{ml}$ proteinase $\mathrm{K}$ in PBS at $37{ }^{\circ} \mathrm{C}$ for $15 \mathrm{~min}$. The sections were then rinsed once with deionized distilled water, and the commercially available kit (ApopTag Plus Peroxidase In Situ Apoptosis Detection Kit; Serologicals Corporation, New York, NY, USA) was used for detection of the $3^{\prime}-\mathrm{OH}$ end of DNA. Endogenous peroxidase activity was blocked by treating the sections with $3 \% \mathrm{H}_{2} \mathrm{O}_{2}$ in PBS for $5 \mathrm{~min}$ at room temperature. The sections were incubated with a mixture of terminal deoxynucleotidyl transferase (TdT) and digoxigenin-labeled dideoxy nucleotide in a humidified chamber at $37^{\circ} \mathrm{C}$ for $1 \mathrm{~h}$. After reaction with stop buffer for $10 \mathrm{~min}$, the sections were incubated with an anti-digoxigenin peroxidase conjugate for $30 \mathrm{~min}$. Peroxidase activity was detected by exposing the sections to a solution containing $0.05 \%$ DAB. The sections were finally counterstained with methyl green. Negative controls were performed using distilled water instead of the TdT enzyme. For statistical analysis, more than 200 round- or oval-shaped seminiferous tubules/animal were counted, and the number of TUNELpositive cells/seminiferous tubule (mean \pm s.D.) in each group was determined.

\section{Analysis of mRNA expression of cytokines by real-time RT-PCR}

To investigate the relationship between the histopathological alteration and cytokine levels in the testes and epididymides, we analyzed the expression of the IL-1 $\alpha(/ / 1 a)$, IL-6 (I/6), IL-10 (I/10), IFN- $\gamma$ (Ifng), and TNF- $\alpha$ (Tnf) genes, using real-time RT-PCR. Total RNA was purified from each fresh tissue sample using TRIZOL reagent (Invitrogen Corp.) according to the manufacturer's protocol, and its concentration was calculated from the extinction at $260 \mathrm{~nm}$ as determined spectrophotometrically. For the first-strand cDNA synthesis, $10 \mu \mathrm{g}$ total RNA was reverse transcribed with a High Capacity cDNA Archive Kit (PE Applied Biosystems, Foster City, CA, USA), according to the standard protocol. Subsequently, $5 \mu \mathrm{l}$ cDNA encoding IL- $1 \alpha$ (ID: Mm00443258-m1), IL-6 (ID: Mm00446190-m1), IL-10
(ID: Mm00439616-m1), TNF- $\alpha$ (ID: Mm00443258-m1), IFN- $\gamma$ (ID: Mm00801778-m1), and $\beta$-actin (ID: Mm00607939-s1) respectively with forward and reverse primers designed from TaqMan primers (PE Applied Biosystems) were amplified by 40 cycles of PCR, carried out with an iCycler thermal cycler (BioRad). Real-time fluorescence-monitored PCR was performed with a PE Applied Biosystems model 7500 Sequence Detection System using TaqMan PCR Master Mix Reagents $2 \times$ and TaqMan Gene Expression Assays of primers 20X, according to the manufacturer's instructions. The results are expressed relative to the amount of $\beta$-actin transcript used as an internal control. In preliminary experiments, testicular cytokines were found to temporally increase during the first 1 week after sham $\vee x$. To exclude the influence of stress such as abdominal incision and s.c. injection, cytokine data from shamVx+PBS group were used as controls in this study.

\section{Statistical analysis}

The significance of differences was analyzed by means of ANOVA. Statistical significance was concluded when $P<0.05$.

\section{Acknowledgment}

This study was supported by a Grant-in-Aid for General Scientific Research (17591704) from the Ministry of Education, Science, Sports and Culture, Japan. The authors declare that there is no conflict of interest that would prejudice the impartiality of this scientific work.

\section{References}

Alexander NJ \& Tung KSK 1977 Immunological and morphological effects of vasectomy in the rabbit. Anatomical Record 188 339-350.

Ansbacher R 1973 Vasectomy: sperm antibodies. Fertility and Sterility 24 788-792.

Aoki A \& Fawcett DW 1975 Impermeability of Sertoli cell junctions to prolonged exposure to peroxidase. Andrologia 7 63-76.

Dym M \& Fawcett DW 1970 The blood-testis barrier in the rat and the physiological compartmentation of the seminiferous epithelia. Biology of Reproduction 3 308-326.

Flickinger CJ, Howards SS, Bush LA, Baker LA \& Herr JC 1994 Temporal recognition of sperm autoantigens by IgM and IgG autoantibodies after vasectomy and vasovasostomy. Journal of Reproductive Immunology 27 135-150.

Flickinger CJ, Howards SS \& Herr JC 1995 Effects of vasectomy on the epididymis. Microscopy Research and Technique 30 82-100.

Gavrieli Y, Sherman Y \& Ben-Sasson SA 1992 Identification of programmed cell death in situ via specific labeling of nuclear DNA fragmentation. Journal of Cell Biology 119 493-501.

Hamilton DW 1972 The mammalian epididymis. In Reproductive Biology, p. 268. Eds $\mathrm{H}$ Balin \& S Glasser. Amsterdam: Exerpta Medica.

Herr JC, Flickinger CJ, Howards SS, Yarbro S, Spell DR, Caloras D \& Gallien TN 1987 The relation between antisperm antibodies and testicular alterations after vasectomy and vasovasostomy in Lewis rats. Biology of Reproduction 37 1297-1305.

Hill N \& Sarvertnick N 2002 Cytokines: promoters and dampeners of autoimmunity. Current Opinion in Immunology 14 791-797.

Howards SS \& Johnson AL 1979 Effects of vasectomy on intratubular hydrostatic pressure in the testis and epididymis. In Vasectomy, Immunologic and Pathophysiologic Effects in Animals and Man, pp 55-66. Eds IH Lepow \& R Crozier. New York: Academic Press. 
Itoh M, Hiramine C \& Hojo K 1991 a A new murine model of autoimmune orchitis induced by immunization with viable syngeneic testicular germ cells alone I. Immunological and histological studies. Clinical Experimental Immunology 83 137-142.

Itoh M, Hiramine C, Tokunaga Y, Mukasa A \& Hojo K 1991 b A new murine model of autoimmune orchitis induced by immunization with viable syngeneic testicular germ cells alone II. Immunohistochemical findings of fully-developed inflammatory lesion. Autoimmunity 10 89-97.

Itoh M, Hiramine C, Mukasa A, Tokunaga Y, Fukui Y, Takeuchi Y \& Hojo K 1992 Establishment of an experimental model of autoimmune epididymo-orchitis induced by the transfer of a T-cell line in mice. International Journal of Andrology 15 170-181.

Itoh M, Miyake M, Miki T, Takeuchi Y \& De-Rooij DG 1994 Immunohistological localization of autoantigens detected by serum autoantibodies from mice with experimental autoimmune orchitis without using adjuvants. Archives of Andrology 32 45-52.

Itoh M, De-Rooij DG \& Takeuchi Y 1995 Mode of inflammatory cell infiltration in testes of mice injected with syngeneic testicular germ cells without adjuvant. Journal of Anatomy 187 671-679.

Itoh M, Ueno M, Li XQ, Satriotomo I \& Takeuchi Y 1998 Topographical uptake of blood-borne horseradish peroxidase (HRP) in the murine testis at the light microscopic level. International Journal of Andrology 21 74-80.

Kaneko T, Itoh M, Nakamura Y, limura A, Hayashi S, Takahashi K, Stivala F, Bendtzen K \& Nicoletti F 2003 Proinflammatory effects of exogenously administered IL-10 in experimental autoimmune orchitis. Cytokine 22 50-53.

Kojima A \& Spencer CA 1983 Genetic susceptibility to testicular autoimmunity: comparison between posthymectomy and postvasectomy models in mice. Biology of Reproduction 29 195-205.

Li L, Itoh M, Ablake M, Macri B, Bendtzen K \& Nicoletti F 2002 Prevention of murine experimental autoimmune orchitis by recombinant human interleukin-6. Clinical Immunology 102 135-137.

Nandipati KC, Pasqualotto FF, Thomas Ag Jr \& Agarwal A 2005 Relationship of interleukin- 6 with semen characteristics and oxidative stress in vasectomy reversal patients. Andrologia 37 131-134.

Nashan D, Cooper TG, Knuth UA, Schubeus P, Sorg C \& Nieschlag E 1990 Presence and distribution of leucocyte subsets in the murine epididymis after vasectomy. International Journal of Andrology 13 $39-49$.
Rival C, Theas MS, Guazzone VA \& Lustig L 2006 Interleukin-6 and IL-6 receptor cell expression in testis of rats with autoimmune orchitis. Journal of Reproductive Immunology 70 43-58.

Roper RJ, Doerge RW, Call SB, Tung KSK, Hickey WF \& Teuscher C 1998 Autoimmune orchitis, epididymitis, and vasitis are immunogenetically distinct lesions. American Journal of Pathology 152 1337-1345.

Rosenbaum JT \& Angell E 1995 Paradoxical effects of IL-10 in endotoxininduced uveitis. Journal of Immunology 155 4090-4094.

Sato K, Hirokawa K \& Hatakeyama S 1981 Experimental allergic orchitis in mice, Histopathological and immunological studies. Virchows Archive (Pathological Anatomy) 392 147-158.

Taguchi O \& Nishizuka Y 1981 Experimental autoimmune orchitis after neonatal thymectomy in the mouse. Clinical and Experimental Immunology 46 425-434.

Tokunaga Y, Terayama H, Naito M, Qu N, Hirai S, Ogawa Y, Yi SQ \& Itoh M 2008 Splenic cytokines in mice immunized with testicular germ cells. International Journal of Andrology [in press]. doi: 10.1111/j.13652605.2007.00790.x.

Tung KSK, Yule TD, Mahi-Brown CA \& Listrom MB 1987 Distribution of histopathology and la positive cells in actively induced and passively transferred experimental autoimmune orchitis. Journal of Immunology $138752-759$.

Verajankorva E, Pollanen P, Hanninen A, Martikainen M, Sundstrom J \& Antola H 2002 IL-10 is highly expressed in the cryptorchid cryptepididymal epithelium: a probable mechanism preventing immune responses against autoantigenic spermatozoa in the epididymal tubule. International Journal of Andrology 25 129-133.

Watanabe M, Kashiwakura Y, Kusumi N, Tamayose K, Nasu Y, Nagai A, Shimada T, Daida H \& Kumon H 2005 Adeno-associated virus-mediated human IL-10 gene transfer suppresses the development of experimental autoimmune orchitis. Gene Therapy 12 1126-1132.

Received 11 January 2008

First decision 12 February 2008

Accepted 25 February 2008 